\section{Estudo \\ cobebate}

em Cestão

Planejamento
Revista Estudo \& Debate, Lajeado, v. 28, n. 4, 2021. ISSN 1983-036X

DOI: http://dx.doi.org/10.22410/issn.1983-036X.v28i4a2021.3022

\title{
LEVANTAMENTO BIBLIOMÉTRICO DOS ESTUDOS COM MEDIDAS DE CONTROLE QUÍMICO E BIOLÓGICO DE Xanthomonas vasicola pv. vasculorum
}

\author{
Taiane Aparecida Ribeiro Nepomoceno ${ }^{1}$, Alex Junior Pietrobon ${ }^{2}$, \\ Leonardo Trevizan Castanheira ${ }^{3}$
}

\begin{abstract}
Resumo: A estria bacteriana do milho (Xanthomonas vasicola pv. vasculorum) está presente em regiōes produtoras do mundo, afetando a milhocultura e causando impactos econômicos. Contudo, pelo fato de ser uma patologia recente na cultura do milho as medidas de controle para o manejo dessa bacteriose sáo escassas. Partindo desse contexto, o levantamento dos estudos referentes aos tipos de controle para essa bacteriose, pode oferecer informaçôes sobre os produtos e espécies mais estudadas no mundo. O principal objetivo deste artigo foi levantar informaçóes bibliométricas sobre o controle químico e biológico de Xanthomonas vasicola pv. vasculorum, no âmbito nacional e internacional. Para isso realizou-se uma varredura em cinco bases de dados, considerando-se estudos no idioma inglês, português e espanhol, em um recorte temporal de 2016 a 2021. O levantamento apontou que o Brasil é o único país com pesquisas publicadas sobre controle químico e biológico para esta bacteriose. Apenas três publicações foram localizadas segundo os critérios de inclusão, publicadas em 2018, 2020 e 2021. Dentre os produtos químicos mais eficientes no controle da bactéria em questáo têm-se aqueles formulados com amônia quaternária, óxido cuproso, oxicloreto de cobre e casugamicina. Em relaçáo ao controle biológico Pseudomonas aeruginosa e Gluconacetobacter diazotrophicus apresentaram potencial antibiótico contra Xanthomonas vasicola pv. vasculorum. No entanto, os achados confirmam a necessidade de maior dispêndio em pesquisas e desenvolvimento de métodos para o controle da estria bacteriana do milho, pois, atualmente existem poucas pesquisas e informaçóes disponíveis na literatura sobre as técnicas de controle químico e biológico para esta espécie.
\end{abstract}

Palavras-chave: Bibliometria. Estria bacteriana do milho. Controle de doenças.

1 Bióloga. Doutoranda em Desenvolvimento Rural Sustentável, Centro de Ciências Agrárias, Universidade Estadual do Oeste do Paraná, Marechal Cândido Rondon, PR, Brasil.

2 Engenheiro Agrônomo, Mestre em Agronomia pela Universidade Estadual do Oeste do Paraná, Corteva Agriscience, Toledo, PR, Brasil.

3 Engenheiro Agrônomo pelo Centro Universitário da Fundação Assis Gurgacz, Ubiratấ, PR, Brasil. 


\title{
BIBLIOMETRIC SURVEY OF STUDIES WITH CHEMICAL AND BIOLOGICAL CONTROL MEASURES OF Xanthomonas vasicola pv. vasculorum
}

\begin{abstract}
Corn bacterial streak (Xanthomonas vasicola pv. vasculorum) is present in producing regions of the world, affecting corn crops and causing economic impacts. However, because it is a recent pathology in corn crop, control measures for the management of this bacteriosis are scarce. Based on this context, the survey of studies on the types of control for this bacteriosis, can provide information on the most studied products and species in the world. The main objective of this article was to collect bibliometric information on the chemical and biological control of Xanthomonas vasicola pv. vasculorum, at the national and international level. For this, a scan was carried out in five databases, considering studies in English, Portuguese and Spanish, in a time frame from 2016 to 2021. The survey pointed out that Brazil is the only country with published research on chemical and biological control for this bacteriosis. Only three publications were located according to inclusion criteria, published in 2018, 2020 and 2021. Among the most efficient chemicals in the control of the bacterium in question are those formulated with quaternary ammonia, cuprous oxide, copper oxychloride and kasugamycin. In relation to biological control Pseudomonas aeruginosa and Gluconacetobacter diazotrophicus presented potential antibiotic against Xanthomonas vasicola pv. vasculorum. However, the findings confirm the need for greater expenditure on research and development of methods for the control of bacterial stria of corn, therefore, there is currently little research and information available in the literature on chemical and biological control techniques for this species.
\end{abstract}

Keywords: Bibliometry. Corn bacterial streak. Disease control.

\section{Introduçáo}

A produção agrícola no Brasil e no mundo é de suma importância para a produção de alimentos, geração de renda e garantia da permanência do homem no campo. Inúmeros fatores podem prejudicar a cadeia da agricultura, como mudanças climáticas, acesso às tecnologias, qualificação profissional e acesso a mercados.

O Brasil como um país que tem se destacado na produção de grãos e devido às suas condiçóes climáticas tropicais, possui os requisitos ideais para o desenvolvimento de inúmeros fitopatógenos. Nesse sentido, entre as principais condiçôes limitantes das culturas agrícolas brasileiras estão as doenças, pragas e plantas daninhas, que afetam as plantaçóes e podem ser entendidos como os principais frustradores de safras (BATISTA et al., 2020).

No caso da cultura do milho (Zea mays), o país enfrenta em algumas regióes específicas ameaças com patógenos emergentes, como a estria bacteriana do milho, causa pela bactéria Xanthomonas vasicola pv. vasculorum (Xvv) (LEITE JÚNIOR et al., 2018). Essa doença foliar, foi descrita pela primeira vez na África do Sul, ao final da década de 40 (PEREZQUINTERO et al., 2020).

Contudo, nos últimos cinco anos foi disseminada para diversas regióes do mundo, atingindo os Estados Unidos (KORUS et al., 2017), Argentina (PLAZAS et al., 2018) e Brasil. Neste último, os primeiros sintomas foram verificados em 2016, afetando mais de 29 municípios do estado paranaense (LEITE JÚNIOR et al., 2018; LEMISKA et al., 2019) e causando diversos impactos para as regióes agrícolas atingidas.

Essa bactéria penetra pelos estômatos ou lesóes na folha de milho e pode ocorrer em qualquer estádio de crescimento da planta. Os sintomas consistem na presença inicial 
de gotículas minúsculas, secas e amarelas nas folhas, que progridem para lesóes finas e alongadas, com bordas amarelas (LEITE JÚNIOR et al., 2018).

A estria bacteriana do milho pode acometer mais de $50 \%$ da área foliar, causando danos irreversíveis e grandes prejuízos à cadeia produtiva. Apesar disso, as informaçóes sobre o controle de $X v v$ são praticamente desconhecidas, pelo fato de se tratar de uma doença consideravelmente recente na cultura do milho (BRODERS, 2017).

Dada a importância econômica dessa bacteriose e a escassez de informaçóes sobre o controle do fitopatógeno, torna-se extremamente importante localizar estudos capazes de descrever diferentes modos de controle para esta doença. Partindo desse contexto, justificase o desenvolvimento da presente pesquisa, pois praticamente nenhum estudo publicado divulga o conjunto bibliográfico sobre controle químico e biológico para $X v v$, sendo fundamental reuni-los e apresentar suas características para esta finalidade.

Por isso, o principal objetivo deste artigo foi levantar informações bibliométricas sobre o controle químico e biológico de Xanthomonas vasicola pv. vasculorum, no âmbito nacional e internacional.

\section{Metodologia}

Esta pesquisa envolveu a coleta e análise de estudos científicos em diferentes regióes do mundo, para verificar a existência de estratégias de controle de $X v v$. Portanto, se caracteriza como uma pesquisa qualitativa e exploratória, elaborada a partir do caráter bibliométrico. Durante os meses de agosto e setembro de 2021 realizou-se um levantamento bibliográfico em cinco bases de dados: i) Web Of Science; ii) Scientific Electronic Library Online (SciELO); iii) Scopus; iv) Google acadêmico; v) Catálogo de teses e dissertaçôes da Coordenação de Aperfeiçoamento de Pessoal de Nível Superior (CAPES).

Para a coleta dos materiais foram utilizados os seguintes descritores, de forma individualizada ou combinados entre si: "Xanthomonas vasicola pv. vasculorum"; "controle" ou "control"; "químico" ou "chemical"; "biológico" ou "biological"; "Zea mays", separados pelo operador booleano "AND”. Foram excluídos da amostra resumos simples e expandidos, monografias, indisponíveis para download, revisóes bibliográficas, em duplicidade ou trabalhos que náo envolvessem diretamente o controle da espécie em questão.

O recorte temporal estabelecido foi de seis anos (2016-2021), considerando-se os estudos no idioma inglês, português e espanhol. A triagem inicial foi desenvolvida a partir da leitura dos títulos, resumo e palavras-chave de estudos publicados na literatura. Consideraram-se apenas os estudos com dados primários, obtidos diretamente com a realização de experimentos envolvendo $X v v$.

A partir disso realizou-se a análise minuciosa e individualizada em cada trabalho, a partir de uma leitura integral. Foram eleitos para a análise aqueles que possuíam resultados correspondentes ao objetivo do presente estudo.

Os dados referentes aos títulos, autor / ano de publicação, categoria da publicação / base de dados, condiçôes de realização dos experimentos, característica específica do método 
de controle adotado e conclusões foram organizados com o auxílio do software Microsoft Excel versão 2010.

\section{Resultados e discussóes}

Em relação à dimensão global alcançada pelo patógeno e perdas econômicas, alguns estudos anteriores já evidenciavam a carência de pesquisas científicas sobre os métodos de controle e medidas de manejo de Xvv. Broders (2017) e Leite Júnior et al. (2018), descrevem que as informações disponíveis sobre o controle efetivo dessa doença são escassas ao nível mundial e ratificam a necessidade do desenvolvimento de experimentos, capazes de contemplar as diversas características da bacteriose e seu agente causador.

No entanto, esses estudos tendem a se concentrar em açóes experimentais, restritas a testes de hipóteses, cujo não envolve uma compreensão mais ampla sobre os tipos de controle já existentes. Em vista disso, realizou-se uma varredura mundial com a intenção de levantar informaçóes das pesquisas com químicos e biológicos para o controle de $X v v$. Entretanto, verificou-se a carência de pesquisas publicadas em relação a esta finalidade. Ao consultar a base de dados da SciELO nenhum resultado foi encontrado, segundo os critérios de busca. Na base da Web of Science identificaram-se 2 estudos, contudo a partir de uma análise mais detalhada constatou-se que eles não correspondiam ao objetivo da pesquisa, pois envolviam outras espécies do gênero Xanthomonas.

Nesse sentido, ao consultar a base de dados da Scopus também se identificou 3 arquivos iniciais, sendo apenas 1 deles incluído na presente revisão. $\mathrm{Na}$ base de dados do Google acadêmico, foram identificados 44 arquivos, contudo ao realizar a leitura flutuante dos títulos, resumos e palavras-chave, foram excluídos da amostra 43 deles, pois apenas 1 atendeu aos critérios de inclusão.

Ao consultar o banco de teses e dissertaçóes da Capes, foi possível identificar inicialmente 3 trabalhos, porém, apenas 1 foi incluído na revisão. Dentre os 2 restantes, 1 deles envolvia o controle genético de $X v v$ e o outro estava em duplicidade, ou seja, era uma dissertação de mestrado publicada em periódico, a qual havia sido encontrada anteriormente na base de dados do Google acadêmico.

No total foram levantadas apenas 3 publicaçóes. O Brasil tem participado ativamente no cenário mundial em pesquisas recentes para o controle de $X v v$, sendo responsáveis pelas 3 publicaçóes (100\%) nos anos entre 2018 e 2021 . Isso pode estar relacionado com o fato de o país ser majoritariamente agrícola e estar voltado à produção de commodities, como o milho a principal cultura afetada pela $X v v$.

Nos últimos anos, o país tem ampliado sua área plantada e produtividade, ganhando local de destaque ao redor do mundo. Apesar do novo arranjo agrícola, causado principalmente pela disponibilidade hídrica que o país tem enfrentado, especialmente na segunda safra 2020/2021, o desempenho das lavouras de milho tem apontado para uma produção de aproximadamente 85,7 milhóes de toneladas (CONAB, 2021).

Cabe destacar que além de ser transportada para novos tecidos e lavouras através de chuva ou águas provenientes de irrigação artificial, $X v v$ pode sobreviver em condiçóes ambientais extremas. Essa bactéria tende a permanecer por longos períodos seja no solo, 
plantas, resíduos culturais, hospedeiros alternativos, como: Avena sativa; Oryza sativa; Dactylis glomerata; Sorghastrum nutans; Andropogon gerardii; Schizachyrium scoparium; Phleum pratense; Andropogon hallii; Setaria viridis; Setaria verticillata; Sorghum halepense e Cyperus esculentus (HARTMAN et al., 2020), sementes ou em uma combinação desses fatores (ORTIZ-CASTRO et al., 2020). A seca como circunstância climática, portanto, não seria um fator limitante para esta bacteriose.

Entretanto, neste estudo o enfoque não envolve os aspectos biológicos dessa espécie, mas sim a produção científica sobre o seu controle. A maioria dos estudos identificados na busca primária não eram coerentes ao objetivo desta pesquisa, pois estavam relacionados com o controle genético, formas de disseminação ou relatórios de comunicação sobre a presença do fitopatógeno em diferentes países.

Embora os dados encontrados sejam limitados épossível identificar um despontamento de estudos no Brasil, preocupados com a adoção de métodos de controle para Xvv. Segundo a pesquisa nas bases de dados e com os critérios adotados, no ano de 2016, 2017 e 2019 nenhum estudo foi publicado em relação à temática em pauta. No entanto, em 2018, 2020 e 2021, foram publicados os três trabalhos respectivamente, como se observa na Figura 1.

Figura 1 - Número de publicaçóes lançadas segundo o levantamento realizado nas bases de dados da Web Of Science, Scientific Electronic Library Online, Scopus, Google acadêmico, catálogo de teses e dissertaçôes da CAPES entre os anos de 2016 e 2021.

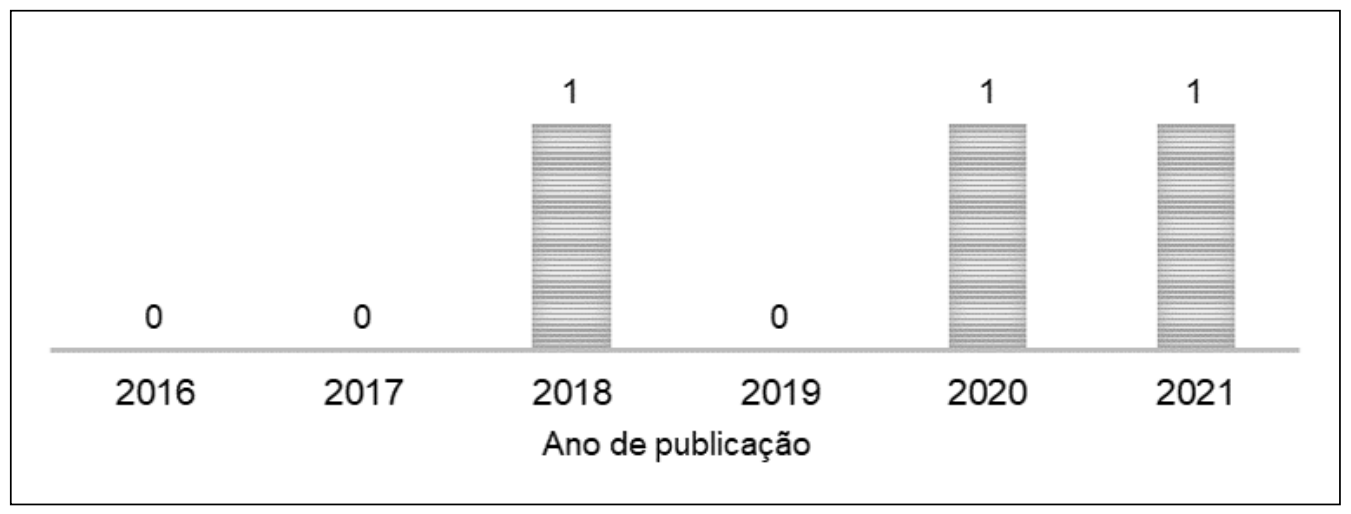

Fonte: dados da pesquisa, 2021.

Dentre os três trabalhos analisados, apenas a dissertação de mestrado em Microbiologia, da Universidade Estadual de Londrina estava em língua portuguesa. As duas outras publicaçôes, em formato de artigo científico, encontravam-se escritos na língua inglesa. Eles estáo publicados em dois periódicos, um do Brasil (Pesquisa Agropecuária Tropical) e outro do Reino Unido (Journal of Applied Microbiology), ambos recebem classificação no estrato B1 para Ciências Agrárias I, segundo a avaliação realizada para o quadriênio 2013-2016 da Qualis/Capes.

No Quadro 1, é possível verificar as informaçóes dos estudos incluídos neste levantamento bibliométrico. 
Quadro 1 - Informações centrais dos estudos incluídos e analisados sobre controle químico e biológico de $X v v$, segundo o levantamento bibliométrico entre os anos de 2016 e 2021.

\begin{tabular}{|c|c|c|c|c|c|}
\hline $\begin{array}{l}\text { Autor / ano de } \\
\text { publicação }\end{array}$ & Título & $\begin{array}{l}\text { Categoria / } \\
\text { Base }\end{array}$ & Condiçốes & $\begin{array}{c}\text { Característica } \\
\text { do controle } \\
\text { adotado } \\
\end{array}$ & Resultados \\
\hline $\begin{array}{l}\text { Pietrobon, } \\
\text { Duarte Júnior e } \\
\text { Kuhn (2021) }\end{array}$ & $\begin{array}{l}\text { Chemical products for } \\
\text { corn bacterial streak } \\
\text { control }\end{array}$ & $\begin{array}{l}\text { Artigo } \\
\text { Científico } \\
\text { / Google } \\
\text { acadêmico }\end{array}$ & $\begin{array}{c}\text { Experimento a } \\
\text { Campo }\end{array}$ & $\begin{array}{l}\text { Controle } \\
\text { químico }\end{array}$ & $\begin{array}{l}\text { Produtos químicos à base } \\
\text { de amônia quaternária, } \\
\text { óxido cuproso, oxicloreto } \\
\text { de cobre e casugamicina } \\
\text { proporcionaram maior } \\
\text { controle da doença }\end{array}$ \\
\hline Piva (2020) & $\begin{array}{c}\text { Atividade } \\
\text { antibacteriana de } \\
\text { compostos produzidos } \\
\text { por Pseudomonas } \\
\text { aeruginosa cepa LV } \\
\text { contra Xanthomonas } \\
\text { vasicola pv. vasculorum } \\
(2020)\end{array}$ & $\begin{array}{c}\text { Dissertação } \\
\text { de mestrado / } \\
\text { Banco de teses } \\
\text { e dissertaçóes } \\
\text { da Capes }\end{array}$ & $\begin{array}{l}\text { Experimento } \\
\text { em casa de } \\
\text { vegetação }\end{array}$ & $\begin{array}{l}\text { Controle } \\
\text { biológico }\end{array}$ & $\begin{array}{c}\text { Os metabólitos } \\
\text { secundários (F4A e o } \\
\text { OAC) de } \\
\text { Pseudomonas aeruginosa } \\
\text { cepa LV apresentaram } \\
\text { ação antimicrobiana } \\
\text { contra Xvv }\end{array}$ \\
\hline $\begin{array}{l}\text { Oliveira et al. } \\
\quad(2018)\end{array}$ & $\begin{array}{c}\text { Gluconacin from } \\
\text { Gluconacetobacter } \\
\text { diazotrophicus PAL5 is } \\
\text { an active } \\
\text { bacteriocin against } \\
\text { phytopathogenic and } \\
\text { beneficial sugarcane } \\
\text { bactéria }\end{array}$ & $\begin{array}{c}\text { Artigo } \\
\text { científico / } \\
\text { Scopus }\end{array}$ & $\begin{array}{l}\text { Experimento } \\
\text { laboratorial }\end{array}$ & $\begin{array}{l}\text { Controle } \\
\text { biológico }\end{array}$ & $\begin{array}{c}\text { A bacteriocina de } \\
\text { Gluconacetobacter } \\
\text { diazotrophicus } \\
\text { denominada } \\
\text { Gluconacina que tem } \\
\text { efeito antagônico contra } \\
X v v .\end{array}$ \\
\hline
\end{tabular}

Fonte: dados da pesquisa, 2021.

Ao analisar as pesquisas constatou-se que elas apresentaram diferentes condiçóes de realização, experimentos em escala laboratorial, casa de vegetação e a campo. Percebese também que produtos cúpricos e outros bactericidas conseguem controlar a doença em condiçóes específicas de campo. E, além disso, verificou-se que algumas espécies de bactérias, a partir da síntese de metabólitos, também apresentam ação antibiótica sobre Xvv.

Como se verifica, $66,6 \%$ dos estudos envolvem o controle biológico de $X v v$, este fato indica haver uma tendência no desenvolvimento de métodos sustentáveis para conter a bacteriose. Isso é coerente à ideia de Maia e Oliveira (2021), que afirmam que o momento atual da agricultura exige a abordagem de técnicas, meios e estratégias capazes de envolver a sustentabilidade e colaborar com a qualidade dos alimentos.

$\mathrm{Na}$ literatura, existe o desenvolvimento de diversas pesquisas científicas com controle alternativo e biológico para outras espécies de Xanthomonas. Sopialena et al. (2021), por exemplo, verificaram que o uso de agentes biológicos, como a bactéria Paenibacilus polymyxa é eficaz no controle da doença das folhas que atinge a cultura do arroz, cuja é causada pelo patógeno Xanthomonas oryzae pv. Oryzae.

De forma semelhante, outra pesquisa testou a eficácia biológica de Bacillus subtilis na mancha bacteriana do feijão-comum. Os resultados obtidos com esta pesquisa comprovaram que a gravidade da doença causada por Xanthomonas axonopodis pv. phaseoli, a taxa de infecção e a incidência dela foram significativamente reduzidas em relação à testemunha (BELETE et al., 2021). 
Além disso, algumas alternativas de controle com extratos vegetais também foram publicadas. Estudos desenvolvidos por Mata et al. (2021), avaliou a atividade antimicrobiana de formulados a base de Rosmarinus officinalis sobre Xanthomonas campestris pv. campestres, causadora da podridão negra em crucíferas. Os resultados obtidos pelos pesquisadores apontam que o formulado orgânico apresentou atividade antimicrobiana eficiente sobre esta espécie, na cultura da couve de folhas.

Por outro lado, Rosenberg et al. (2020) estudaram alternativas de controle para a bacteriose da mandioca, provocada por Xanthomonas axonopodis pv. manihotis. Nesse experimento, os autores constataram que os extratos de Coix lacryma-jobi náo apresentaram atividade antibacteriana frente ao agente causal da bacteriose da mandioca.

No entanto, esses estudos já publicados não eram consistentes com a espécie Xvv causadora da estria bacteriana do milho. Ademais, observa-se que nos três estudos analisados na presente, o enfoque é direcionado para o controle desta bacteriose em milho e canade-açúcar. $\mathrm{O}$ desenvolvimento dessas pesquisas permite identificar as interaçôes existentes entre o agente patogênico e os elementos de controle, especialmente os biológicos como uma alternativa promissora e menos danosa ao meio ambiente.

Para isso foi utilizada a abordagem bibliométrica qualitativa, de modo a levantar os estudos publicados na literatura mundial sobre controle químico e biológico da bactéria $X v v$. Usando esta abordagem verificou-se uma ampla carência de pesquisas contemplando uso e aplicação dessas técnicas, conforme descrito por Pietrobon, Duarte Júnior e Kuhn (2021). No entanto, esses resultados sugerem que o desenvolvimento de novas pesquisas nessa área pode fornecer meios a implementação de estratégias com grandes impactos positivos à agricultura.

\section{Consideraçóes finais}

Nesta pesquisa, realizou-se o levantamento de informaçóes científicas sobre o panorama nacional e internacional de pesquisas com produtos químicos e biológicos para o controle de $X v v$, causadora da estria bacteriana do milho, a qual vem gerando grandes prejuízos nas lavouras de diversos países. Verificou-se que, até o momento de realização desta análise bibliométrica existem apenas três estudos publicados na literatura, associados com o controle químico, mas principalmente com o controle biológico desta bacteriose.

Esses achados ainda demonstram que todas as pesquisas foram desenvolvidas por brasileiros e publicadas em periódicos científicos. Isso confirma a necessidade de um maior dispêndio em pesquisas e desenvolvimento de métodos de controle, para a estria bacteriana do milho, quer no Brasil ou em outros países. Além disso, os resultados obtidos no presente estudo não se relacionam com o controle genético ou híbridos utilizados nos experimentos, mas sim com as peculiaridades de efetividade desses controles sobre a bacteriose.

A partir da análise dos estudos publicados, notou-se que no controle químico os formulados com amônia quaternária, óxido cuproso, oxicloreto de cobre e casugamicina conseguem controlar a doença. E, em relação ao controle biológico, Pseudomonas aeruginosa e Gluconacetobacter diazotrophicus demonstraram ação antibiótica contra Xvv, segundo as condiçóes dos experimentos. 
Portanto, esta pesquisa demonstra que os benefícios de controle biológico e químico evidenciados pelos estudos analisados, podem atender às necessidades dos produtores. Apesar disso, defende-se a necessidade de uma agricultura sustentável, com a utilização de métodos capazes de garantir o controle de $X v v$, a qualidade de vida para o agricultor e a produtividade, numa lógica de sustentabilidade dos sistemas.

Ademais, esta é uma das primeiras pesquisas bibliométricas capazes de investigar e reunir estudos publicados que envolvem o controle de $X v v$. Assim, os resultados fornecem grande evidências sobre a carência de pesquisas e informaçóes técnicas de controle químico e biológico para esta espécie e, logo sugerem que esta abordagem tende a ser aprimorada a partir do uso de extratos vegetais.

Contudo, algumas limitaçóes precisam ser evidenciadas. Esta pesquisa, apesar de ser rigorosamente metodológica, apoia-se na coleta de estudos de controle químico e biológico, mas não envolve nenhum aspecto relacionado ao controle genético, pelo uso de híbridos resistentes. Assim, sugere-se que um trabalho futuro inclua uma pesquisa detalhada em mais bases de dados mundiais e englobe o controle genético como uma possível variável de busca dos materiais.

\section{Referências}

BATISTA, C. D.; BARBOSA, M. G.; OLIVEIRA, R. C. M.; PASTORI, P. L. Percepção da utilização do manejo integrado de pragas por produtores rurais da regiấo da Serra da Ibiapaba, Ceará. Pesquisa, Sociedade e Desenvolvimento, v. 9, n. 11, p. 2-25, 2020.

BELETE, T.; BASTAS, K. K.; FRANCESCONI, S.; BALESTRA, G. M. Biological effectiveness of Bacillus subtilis on common bean bacterial blight. Journal of Plant Pathology, v. 103, n. 1, p. 249-258, 2021.

BRODERS, K. Status of bacterial leaf streak of corn in the United States. In: INTEGRATED CROP MANAGEMENT CONFERENCE, 29., 2017, Ames. Proceedings... Ames: ICM, 2017. p. 111-115.

CONAB. Companhia Nacional de Abastecimento. Acompanhamento da safra brasileira de gráos: Décimo segundo levantamento. Brasília: CONAB, 2021.

HARTMAN, T.; THARNISH, B.; HARBOUR, J.; YUEN, G. Y.; JACKSON-ZIEMS, T. A. Alternative Hosts in the Families Poaceae and Cyperaceae for Xanthomonas vasicola pv. vasculorum, Causal Agent of Bacterial Leaf Streak of Corn. Phytopathology, v. 100, n. 1, p. 1147-1152, 2020.

KORUS, K.; LANG, J. M.; ADESEMOYE, A. O.; BLOCK, C. C.; PAL, N.; LEACH, J. E.; JACKSON-ZIEMS, T. A. First report of Xanthomonas vasicola causing bacterial leaf streak on corn in the United States. Plant Disease, v. 101, n. 6, p. 1030-1030, 2017. 
LEITE JÚNIOR, R. P.; CUSTÓDIO, A. A. P.; MADALOSSO, T.; ROBAINA, R. R.; DUIN, I. M.; SUGAHARA, V. H. Estria bacteriana do milho no Paraná. Londrina: Iapar, 2018.

LEMISKA, A.; SORANSO, M.; CARVALI, N. C.; ARAÚJO, M. M.; BRANDÃO, P. R. P.; CUSTÓDIO, A. A. P. Disseminação da estria bacteriana do milho (Xanthomonas vasicola pv. vasculorum) no Paraná. In: V CONGRESSO BRASILEIRO DE FITOSSANIDADE. 5., 2019. Curitiba. Anais... Curitiba: UNESP, 2019. p. 1-1.

MAIA, B. J.; OLIVEIRA, E. C. Segurança alimentar, agricultura familiar e abastecimento de alimentos em tempos de pandemia: ensaios para o estado do Amazonas. Estudo \& Debate, v. 28, n. 1, p. 118-140, 2021.

MATA, T. C.; STANGARLIN, J. R.; KUHN, O. J.; LORENZETTI, E.; CARVALHO, J. C.; DEMARTELAERE, A. C. F.; BRITO, O. D. C.; COSTA, A. P.; ASSI, L. Atividade antimicrobiana de formulados a base de alecrim contra Xanthomonas campestris pv. Campestris e Alternaria brassicae. Brazilian Journal of Development, v. 7, n. 9, p. 9422094236. 2021.

OLIVERA, M. M.; RAMOS, E. T. A.; DRECHSEL, M. M.; VIDAL, M. S.; SCHWAB, S.; BALBANI, J. L. Gluconacin from Gluconacetobacter diazotrophicus PAL5 is an active bacteriocin against phytopathogenic and beneficial sugarcane bacteria. Journal of Applied Microbiology, v. 125, n. 1, p. 1812-1826, 2018.

ORTIZ-CASTRO, M. O.; HARTMAN, T.; COUTINHO, T.; LANG, J. M.; KORUS, K.; LEACH, J. E.; JACKSON-ZIEMS, T.; BRODERS, K. Current understanding of the history, global spread, ecology, evolution, and management of the corn bacterial leaf streak pathogen, Xanthomonas vasicola pv. vasculorum. Phytopathology, v. 110, n. 6, p.1124-1131, 2020.

PEREZ-QUINTERO, A. L.; ORTIZ-CASTRO, M.; WU, G.; LANG, J. M.; LIU, S.; CHAPMAN, T. A.; CHANG, C.; ZIEGLE, J.; PENG, Z.; WHITE, F. F.; PLAZAS, M. C.; LEACH, J. E.; BRODERS, K. Genomic acquisitions in emerging populations of Xanthomonas vasicola pv. vasculorum infecting corn in the U.S. and Argentina.

Phytopathology, v. 110, n. 6, p. 1161-1173, 2020.

PIETROBON, A. J.; DUARTE JÚNIOR, J. B.; KUHN, O. J. Chemical products for corn bacterial streak control. Pesquisa Agropecuária Tropical, v. 51, n. 1, p. 1-7, 2021.

PIVA, A. C. M. Atividade antibacteriana de compostos produzidos por Pseudomonas aeruginosa cepa LV contra Xanthomonas vasicola pv. vasculorum. 87 f. 2020.

Dissertação (Mestrado em Microbiologia) - Universidade Estadual de Londrina, Londrina, 2020. 
PLAZAS, M. C.; WU, G.; ROSSI, R.; BRUCHER, E.; GUERRA, F. A.; VILARÓ, M.; GUERRA, G. D.; ORTIZ-CASTRO, M. C.; BRODERS, K. First Report of Xanthomonas vasicola pv. vasculorum causing bacteria leaf streak of maize (Zea mays) in Argentina. Plant Disease, v. 102, n. 5, p. 1026-1026, 2018.

ROSENBERG, M. G.; AMATUZI, J. C. A.; ROSENBERG, A. G.; ZONETTI, P. C. PAULERT, R. Atividade antimicrobiana de extrato de Coix Lacryma-jobi sobre Xanthomonas axonopodis pv. Manihotis e Fusarium graminearum. Revista Agronegócio e Meio Ambiente, v. 13, n. 1, p. 135-148, 2020.

SOPIALENA, S.; JANNAH, R.; TANTIANI, D. Control of bacterial leaf blight disease in several varieties of rice plants (Oryza sativa L.) by using bacteria of Paenibacilus polymyxa Mace. Earth and Environmental Science, v. 800, n. 1, p. 1-9, 2021. 